\title{
Epidemiological and Therapeutic Aspects of the Vaginal Hydroceles
}

\author{
Mamadou Alymami Keita1, Abdoulaye Kanté1,2*, Drissa Ouattara1, Bréhima Bengaly1, \\ Bréhima Coulibaly¹, Drissa Traoré1, Siaka Diallo', Babou Ba ${ }^{2}$, Djibril Traoré3, Mariam Daou ${ }^{4}$, \\ Bakary Keita ${ }^{5}$, Birama Togola1, Nouhoum Ongoïba1
}

\author{
${ }^{1}$ Service of Surgery B. CHU Point G. Bamako, Mali \\ ${ }^{2}$ Laboratory of Anatomy of the Faculty of Medicine and Odontostomatology, Bamako, Mali \\ ${ }^{3}$ Service of General Surgery, Sominé Dolo of Mopti hospital, Bamako, Mali \\ ${ }^{4}$ Service of Neurology, CHU Gabriel Touré, Bamako, Mali \\ ${ }^{5}$ Service of General Surgery, Gabriel Touré, Bamako, Mali \\ Email: *kanteim@yahoo.fr
}

How to cite this paper: Keita, M.A., Kanté, A., Ouattara, D., Bengaly, B., Coulibaly, B., Traoré, D., Diallo, S., Ba, B., Traoré, D., Daou, M., Keita, B., Togola, B. and Ongoïba, N. (2018) Epidemiological and Therapeutic Aspects of the Vaginal Hydroceles. Surgical Science, 9, 474-479.

https://doi.org/10.4236/ss.2018.912054

Received: August 15, 2018

Accepted: October 20, 2018

Published: December 19, 2018

Copyright (C) 2018 by authors and Scientific Research Publishing Inc. This work is licensed under the Creative Commons Attribution International License (CC BY 4.0).

http://creativecommons.org/licenses/by/4.0/

\section{(c) (i) Open Access}

\begin{abstract}
Purpose: Our purpose was to describe the epidemiological and therapeutic aspects of the vaginal hydroceles. Methodology: It was a forward-looking and descriptive study of Mars 2014 in July, 2017, which realized in the service of general surgery of the Reference Health Center of Kati (Mali). All the patients operated in the service for hydrocele were included. Other causes of big stock exchange and hydroceles operated outside our service were not including. Results: We operated 92 hydroceles or $5.9 \%$ of the surgical activities of the service. The average age was of 34.5 years with extremes of 2 years and 82 years. The most frequent signs of hydrocele were the big painless stock exchange (100\%); a transillumination positive (90\%) and the effusion of the vaginal in the ultrasound (100\%). The cure of hydrocele was realized according to the techniques of Bergmann (94.6\%) and of Lord (5.4\%). The mortality was nil and the morbidity was $3.3 \%$ (2 operating infections of the site and 1 bruise). Conclusion: The hydrocele is a frequent pathology in Africa. The therapeutic strategies are multiple and varied. However, we prefer the Bergmann technique, which is easy, fast and has few complications.
\end{abstract}

\section{Keywords}

Vaginal Hydrocele, Surgery, Bamako (Mali)

\section{Introduction}

The hydrocele is a liquid collection between the leaves of the vaginal of the testicle. Mild affection, it is the $3^{\text {rd }}$ talks of big stock grant at the adult, behind orc- 
hi-epididymitis and Hernia inguinoscrotal [1].

The etiology arouses numerous discussions, but both main clauses are the congenital hydroceles by obstinacy of the peritonea-vaginal canal and the acquired hydroceles [2].

The diagnosis of the hydrocele is clinical [3]. In case of doubt only the testicular ultrasound may be asked because of its sensibility and because of its specificity [4].

The surgical treatment of the hydrocele is at present codified well and rests mainly on the techniques of Bergmann and of Lord [3].

We introduced this study as objective to describe the epidemiological and therapeutic aspects of the vaginal hydroceles.

\section{Materials and Methods}

\subsection{Patients}

It was about a forward-looking and descriptive study of Mars 2014 in July, 2017, realized in the service of general surgery of the Reference health center of Kati (Mali).

All the patients operated in the service for hydrocele in the service during the period of study were included. Other causes of big stock exchange and hydroceles operated except our service were not including.

\subsection{Methods}

The operated sick were listed by the Technical directors of the Centers being of the Reference health center, the community relays and by the surgeons.

A complete clinical examination, an ultrasound if necessary, a preoperative biological balance sheet and a consultation of anesthesia were realized at all the sick.

The studied variables were: the sociodemographic characteristics, the clinical signs and paracliniques, the operating techniques, the post-operative suites.

These data were seized and analyzed on the software Ear Information (version 6). The test of $\mathrm{Khi}^{2}$ and Student were used to compare our results to those of the other authors. The threshold of meaning was fixed to 0.05 .

\section{Results}

We operated 92 hydroceles or $5.9 \%$ of the surgical operations (1547 interventions) during the period of study.

\subsection{Sociodemographic Data}

The average age was of 34.5 years with extremes of 2 years and 82 years. The age bracket of 18 years and more represented $81.5 \%$. The patients came outside Kati in 86 cases (93.5\%) and lived in Kati in 6 cases (6.5\%). The operated were infants in 5 cases (5.4\%), children in 12 cases (13.1\%), and adults in 75 cases (81.5\%) (Table 1). 
Table 1. Age bracket of the patients.

\begin{tabular}{ccc}
\hline Age brackets (years) & Number & Percentage (\%) \\
\hline $0-2$ & 5 & $5.4 \%$ \\
$2-18$ & 12 & $13.1 \%$ \\
18 and plus & 75 & $81.5 \%$ \\
Total & 92 & $100 \%$ \\
\hline
\end{tabular}

\subsection{Clinical Signs and Paracliniques}

All the patients had a big painless stock exchange (100\%) and the transillumination (Figure 1) was positive in $90 \%$. The hydrocele was to the right in $54.3 \%$ (50 sick), to the left in $32.1 \%$ (30 sick) and bilateral in $13.4 \%$ (12 sick) (Figure 2).

The ultrasound asked at 10 patients found a unilateral effusion in 6 cases and bilateral in 4 cases (Figure 3 ).

In $4.3 \%$ a surgical pathology was associated with the hydrocele (an adenoma of the prostate, a hernia homolateral, a hernia inguinoscrotal homolateral and an umbilical hernia) (Figure 4).

\subsection{Techniques and Operating Consequences}

The local anesthetic in the xylocaine $2 \%$ was used in $80.2 \%$, the general anesthesia in $13.7 \%$ and the spinal anesthesia $6.1 \%$.

The inguinal manner was realized in $16.3 \%$ at the patients under age 15 whereas a scrotal manner either on the median raphe or the transverse side scrototomy was practiced at $83.7 \%$.

The plicature simple of the vaginal according to Lord was realized at $5 \mathrm{pa}$ tients $(5.4 \%)$ and the resection of the vaginal according to Bergmann at $87 \mathrm{pa}-$ tients $(94.6 \%)$.

In three cases the cure of hydrocele was associated with a hernia cure and in a case in an adenectomy transvesical of the prostate.

The operating mortality was nil and the morbidity was 3.3\% made by 2 infections of the operating site and by a bruise of stock exchange the evolution of which was favorable in every case under treatments surgical (evacuations-drainages and local care) and medical (analgesic, anti-inflammatory, antiseptic and antibiotic).

\section{Discussion}

The vaginal hydrocele is a mild, frequent pathology still on the African continent [1] [3] [5]. The diagnosis is clinical often confirmed in the testicular ultrasound; the reference treatment is surgical [6] because it is the effective only one with its two major principles of radical cure. So the interventions for hydrocele represented $5.9 \%$ of the surgical activities of the Reference health center of Kati. Our rate is close to $4.4 \%$ reported by Boukinda F. and Nervetti G. The ascendancy of hydroceles to the old subject described in the literature [7] was 


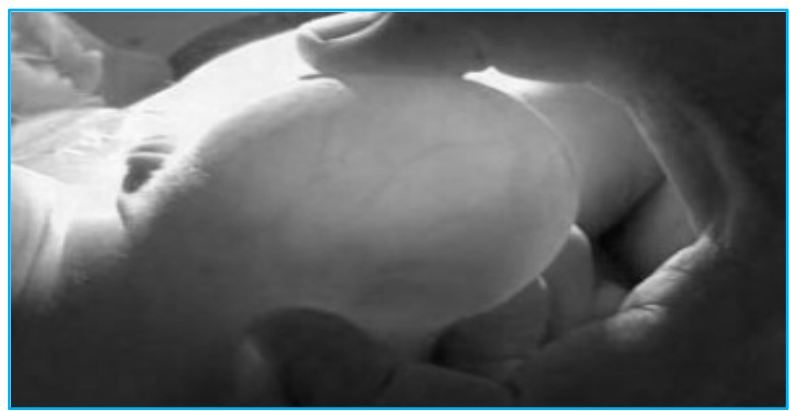

Figure 1. Transillumination is positive at a child's of 2ans.

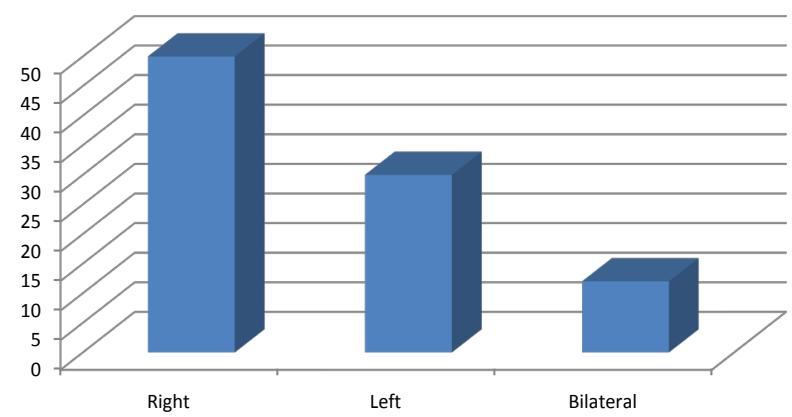

Figure 2. Localization of the hydrocele at the patients.

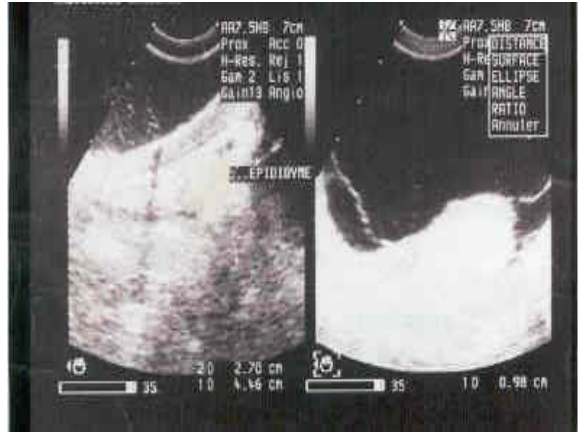

Figure 3. Primitive compartmentalized hydrocele in the testicular ultrasound.

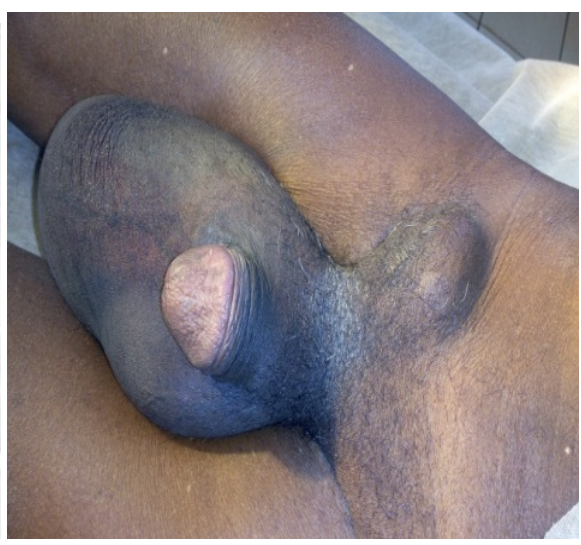

Figure 4. Right hydrocele + HID. 
observed in our study. According to Sewa and al [3] in Togo it could give some explanation in Africa by the delay of consultation where the traditional treatments are usually the first appeal.

The ultrasound is the complementary examination of choice in case of doubt diagnosis. It presents a very high sensibility and specificity. During our study, the testicular ultrasound was realized at $10.9 \%$ of our sick and objectified an effusion. This sensibility is also reported by the study of Sougoule S. [4].

Thehydrocele can affect a stock exchange or both (Figure 5). We found a right ascendancy as Boukinda F. and al. [5] whereas Saata S. and al. [7] reported a left ascendancy. No argument was found in the literature being understandable the right or left ascendancy.

All our sick benefited from a radical cure or according to the technique of Lord (5 patients or according to the technique of Bergmann (87 patients). For many authors [3] [5] as we, the partial resection and the reversal of the vaginal are enough. The therapeutic result is generally excellent and second offenses are exceptional. Two ways at first were used in our series, the inguinotomy at the children at least of 15 ans and the scrototomy beyond. But in way Dress rehearsal the scrototomy was the rule for the voluminous hydroceles whatever is the age because their display by an inguinal way was difficult. Of the blow the notices are shared in the literature as it is a question of inguinotomy or scrototomy in the cure of hydrocele. If the inguinal section was the only one practiced in a study carried out in Dakar [8], realized at all the children of a pediatric series of 117 whose age varied between 22 months and 15 years, certain authors [1] [3] [9] prefer the scrototomy because according to them it entails not much risk of deferential and nervous lesion on one hand and on the other hand because of its speed of execution.

Besides it assures a good healing. We think that whatever is the way at first, most importing is to practice the good technique of cure with the good way. So in spite of a therapeutic arsenal of hydrocele containing several methods and techniques going of the sclerotherapy to the open-air surgery, we preferred the radical surgery in the grip load hydroceles because of its precision, of its efficiency, its speed, the rarity of the complications and the second recurrences. After one year of backward drop the morbidity was 2 infections of the operating site and the bruise and the mortality was nil. The absence of post-operative

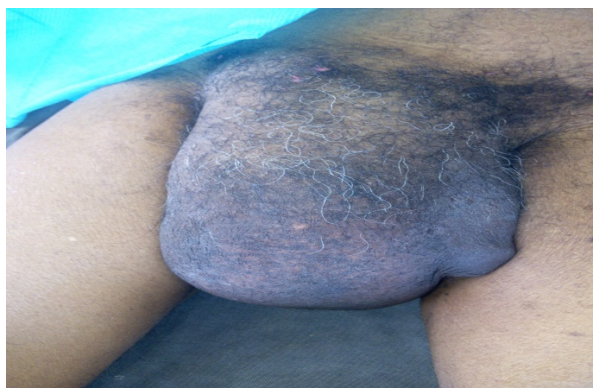

Figure 5. Bilateral Hydrocele. 
major complications was described in the literature by certain authors [3] [10] having practiced these surgical techniques, that is why we consider that they are in our conditions the reference methods in the treatment of hydroceles.

\section{Conclusion}

The hydrocele is a frequent pathology in Africa. The therapeutic strategies are multiple and varied. However, we prefer the Bergmann technique, which is easy, fast and has few complications.

\section{Conflicts of Interest}

We, authors of this article declare that there is no conflict of interests.

\section{Authorization of the Ethics Committee}

We, undersigned, authors of this article give evidence that we received the authorization of the Ethics Committee for the realization of this study.

\section{References}

[1] Chiron, P., Amadane, N., Hat, S., et al. (2014) Cure of Hydrocele by a General Surgeon in Office Isolated in Africa. Tropical Medicine and Health, 24, 32-38.

[2] Buzzi, C.A. (1890) Of the Hydrocele Generally and Its Treatment in Particular According to the Method Julliard. Doctoral Thesis, Univ. Geneva.

[3] Sewa, H., Avakoudjo, J.D., Tengue, K.K., et al. (2016) Epidemiological and Therapeutic Aspects of the Vaginal Hydroceles in the Regional Hospital of Dapaong (Togo). African Journal of Urology, 22, 315-318. https://doi.org/10.1016/j.afju.2016.04.001

[4] Sougoule, S. (2005) Contribution of the Ultrasound in the Diagnosis of the Inguino-Scrotal Affections, about 42 Cases. Thesis med. Bamako (Mali).

[5] Boukinda, F. and Nervetti, G. (2003) The Vaginal Hydrocele. About 55 Operated Cases. Annals of Urology, 37, 293-295. https://doi.org/10.1016/S0003-4401(03)00108-6

[6] Falandry, L. and ME Pouho-Apouba, L. (1993) The Vaginal "Window" in the Cure of the Hydroceles Idiopathic of the Adult a Simple and Reliable Process. African Journal of Medicine, 10, 40.

[7] Sataa, S., Mohamed, B. and Sami, B.R. (2011) The sclérotherapyin the Polidocanol in the Treatment of the Vaginal Hydroceles Idiopathic: Study about 190 Cases. $T u-$ nisia Journal of Medicine, 89, 440-444.

[8] Gabriel, N., Azhar, S., Mehdihas, D., et al. (2016) The Hydrocele by Persistence of the Peritonea-Vaginal Channel in Dakar: About 117 Cases. International Newspaper of Innovation and Scientific Research, 26, 100-104.

[9] Tariel, E. and Mongiat, A. (2004) Treatment of the Hydroceles of the Adult. Annals of Urology, 38, 180-185. https://doi.org/10.1016/j.anuro.2004.05.002

[10] Nomtondo, O., Sounded, B. and Traore, F. (2016) Impact of the Treatment of Mass of Filariose Lymphatique by Albendazole-Ivermectine in Zone of Savanna: Case of the Region from the East of Burkina. 4, 17. 